\title{
Effect of Temperature on Growth and Sporulation of US-22, US-23, and US-24 Clonal Lineages of Phytophthora infestans and Implications for Late Blight Epidemiology
}

\author{
Anna C. Seidl Johnson, Kenneth E. Frost, Douglas I. Rouse, and Amanda J. Gevens
}

Department of Plant Pathology, University of Wisconsin-Madison, Madison, 53706.

Accepted for publication 20 October 2014.

\begin{abstract}
Seidl Johnson, A. C., Frost, K. E., Rouse, D. I., and Gevens, A. J. 2015. Effect of temperature on growth and sporulation of US-22, US-23, and US-24 clonal lineages of Phytophthora infestans and implications for late blight epidemiology. Phytopathology 105:449-459.

Epidemics of late blight, caused by Phytophthora infestans (Mont.) de Bary, have been studied by plant pathologists and regarded with great concern by potato and tomato growers since the Irish potato famine in the 1840s. P. infestans populations have continued to evolve, with unique clonal lineages arising which differ in pathogen fitness and pathogenicity, potentially impacting epidemiology. In 2012 and 2013, the US-23 clonal lineage predominated late blight epidemics in most U.S. potato and tomato production regions, including Wisconsin. This lineage was unknown prior to 2009. For isolates of three recently identified clonal lineages of $P$. infestans (US-22, US-23, and US-24), sporulation rates were experimentally determined on potato and tomato foliage and the effect of temperature on lesion growth rate on tomato was investigated. The US-22 and US-23 isolates had greater lesion growth rates on tomato than US-24 isolates. Sporulation rates for all isolates were greater on potato than tomato, and the US-23 isolates had greater sporulation rates on both tomato and potato than the US-22 and US-24 isolates. Experimentally determined correlates of fitness were input to the LATEBLIGHT model and epidemics

lineages on late blight epidemiology. The fast lesion growth rates of US-22 and US-23 isolates resulted in severe epidemics in all years tested, particularly in 2011. The greater sporulation rates of $P$. infestans on potato resulted in simulated epidemics that progressed faster than epidemics simulated for tomato; the high sporulation rates of US-23 isolates resulted in simulated epidemics more severe than simulated epidemics of isolates of the US-22 and US-24 isolates and EC-1 clonal lineages on potato and tomato. Additionally, US-23 isolates consistently caused severe simulated epidemics when lesion growth rate and sporulation were input into the model singly or together. Sporangial size of the US-23 isolates was significantly smaller than that of US-22 and US-24 isolates, which may result in more efficient release of sporangia from the tomato or potato canopy. Our experimentally determined correlates of fitness and the simulated epidemics resulting from their incorporation into the LATEBLIGHT model suggest that US-23 isolates of $P$. infestans may have the greatest fitness among currently prevalent lineages and may be the most likely lineage to persist in the $P$. infestans population. The US-23 clonal lineage has been documented as the most prevalent lineage in recent years, indicating its overall fitness. In our work, US-23 had the highest epidemic potential among current genotypes. Given that epidemic potential is a component of fitness, this may, in part, explain the current predominance of the US-23 lineage.
\end{abstract} were simulated using archived Wisconsin weather data from four growing seasons (2009 to 2012) to investigate the effect of isolates of these new

Late blight, caused by the oomycete Phytophthora infestans (Mont.) de Bary, is one of the most devastating diseases of potato and tomato production worldwide, costing an estimated $\$ 6.7$ billion annually to potato production (34). In U.S. potato production, it is estimated that $\$ 77.1$ million per year is spent on late blight management, yet crop losses are still estimated to be $\$ 287.8$ million annually (32). Yield losses to late blight in fresh and processing tomato reached \$23 million and \$33 million, respectively, in 2009 (35) (http://www.nass.usda.gov/Data_Statistics/Quick_Stats/).

Genetic change of this pathogen in northern North America has been limited, due mainly to the lack of widespread sexual recombination $(15,20,28,39,49)$. As such, the concept of clonal lineages, or asexual descendants of a single genotype, has been useful for studying the population (18). Isolates within a clonal lineage generally have identical genotypic characteristics such as restriction fragment length polymorphism fingerprints at the RG57 locus (25) and allozyme genotypes (27), and share similar phenotypic characteristics such as sensitivity to the systemic fungicide mefenoxam

Corresponding author: A. J. Gevens; E-mail address: gevens@wisc.edu

http://dx.doi.org/10.1094/PHYTO-03-14-0064-R

(c) 2015 The American Phytopathological Society
Additional keywords: LATEBLIGHT simulation model.

and mating type $(14,31,44,49)$. Typically, these genotypic characteristics are promptly determined for each new lineage discovered $(21-23,41)$ but other epidemiologically important phenotypic characteristics such as sporangial production, lesion growth rate (LGR), and temperature preference are less routinely explored with isolates within a genotype. Sporangial production and LGR by $P$. infestans has been determined for isolates of several lineages, including US-1 $(43,45,46)$, US-6 (43), US-7 $(43,45,46)$, US-8 $(43,45,46)$, US-11 (45), and multiple isolates not assigned a US-number distinction $(4,38,43,45,51)$. The effect of temperature on life stages of $P$. infestans has also been reported for several clonal lineages. In 1934, Crosier (12) investigated the influence of temperature on lesion growth and sporulation of isolates likely from a single clonal lineage, US-1, which was widespread and believed to be the only lineage present at the time. More recently, Mizubuti and Fry (46) explored the effect of temperature on incubation period, lesion area, and sporangial production on the US-1, US-7, and US-8 clonal lineages. However, the US- 1 clonal lineage of $P$. infestans has not been found in the United States in recent years and the US-7 and US-8 lineages have declined $(13,37,49)$. The US-22, US-23, and US-24 lineages have become predominant in the United States since 2009, with detections of US-23 making up the majority of the late blight isolates characterized in a national collection (primarily housed in the laboratory of Dr. W.E. Fry at Cornell University), 
suggesting a higher level of apparent fitness of US-23 isolates and compared with other recent lineages $(6,13,49)$.

For plant pathogens, including $P$. infestans, fitness is defined as the relative ability of the organism to survive, reproduce, and cause disease $(1,7)$. Many biological characteristics, including but not limited to the ability of a particular isolate or clonal lineage to produce more sporangia $(13,46)$, survive at broader temperature ranges $(12,46)$, infect a wider range of hosts $(24,30)$, or have greater rates of direct or indirect germination (13), can all increase the probability that a particular isolate or clonal lineage will be able to successfully survive, reproduce, and cause disease (7).

Simulation modeling can be used to analyze the effects of changes in epidemic potential and correlates of pathogen fitness $(10,16,40)$. One of the first models, called LATEBLIGHT, was developed in 1981 by Bruhn and Fry (10) to determine the combination of rate-reducing resistance and fungicide scheduling that would optimize disease management in potato. This model was further refined by Doster et al. (16) by adding a simple host growth submodel and adjusting parameters to be more consistent with field observations. The model was then used to integrate fungicide usage with partial plant resistance to minimize selection of $P$. infestans genotypes that were insensitive to the fungicide metalaxyl (16). In both studies, model predictions were compared with observed late blight epidemics in New York for model validation. More recently, the LATEBLIGHT model was further refined by Andrade-Piedra et al. (4) to include the effect of temperature on latent period and update the equations describing the effect of temperature on LGR and sporulation rate (SR) for more recently identified $P$. infestans clonal lineages. The revised model was validated by comparing model predictions to late blight epidemics in the Peruvian Andes (5). Since then, the LATEBLIGHT model has been validated using data from epidemics occurring in Ecuador, Israel, Mexico, Nicaragua, and the United States and accurately predicted late blight epidemic progression across this broad geographic range $(3,9)$.

The objectives of this research were to quantify correlates of fitness of isolates of the US-22, US-23, and US-24 clonal lineages of $P$. infestans and examine whether those correlates of fitness substantiated the observed pattern of persistence of $P$. infestans clonal lineages in Wisconsin. To complete these objectives, the effect of temperature on mycelial and sporangial growth was measured and the SR was quantified on potato and tomato for multiple isolates of $P$. infestans belonging to the US-22, US-23, and US-24 clonal lineages. The average sporangial size of isolates belonging to each lineage was also determined due to the potential implication for dispersal or survival of the pathogen. To examine how the measured differences in growth or sporulation among isolates of the different clonal lineages could affect disease progression in the field, we modified the pathogen growth and sporulation parameters in the LATEBLIGHT simulation model (4) to reflect our results and simulated epidemics using 4 years of weather data from the major production region of Wisconsin.

\section{MATERIALS AND METHODS}

$P$. infestans isolates. All isolates of P. infestans were collected from Wisconsin potato and tomato fields or home gardens during 2009, 2010, and 2011. Five isolates each of US-22, US-23, and US24 were selected as representatives from a larger collection (49). The 15 representative isolates were collected from different years, locations, hosts, and plant organs (Table 1). Isolates were maintained in hemp seed long-term storage vials (42) in the Vegetable Pathology pathogen collection in the Plant Pathology Department at the University of Wisconsin-Madison. Isolates were transferred minimally in culture and all LGR experiments were performed within 18 months of isolate collection to minimize any loss of virulence $(29,36)$. Most of the sporangia quantification experiments were performed at a later date and, to ensure virulence, each of these isolates was passed through potato and tomato leaf tissue twice before inoculating the potato and tomato leaves from which sporangia were quantified.

Temperature effect on LGR. Inoculum was prepared from 3 -week-old $P$. infestans cultures actively growing on rye A agar medium (11). To harvest sporangia, culture plates were flooded with sterile distilled water and brushed gently with a sterile glass rod to dislodge sporangia, and the resulting suspensions were placed in sterile plastic $50-\mathrm{ml}$ centrifuge tubes. Suspensions were quantified using a hemacytometer and concentrations were adjusted to 50,000 sporangia/ml using sterile distilled water.

A detached-leaf assay was conducted to determine LGR $(43,53)$. Six tomato leaflets ('Brandywine Red'; Reimer Seed, Saint Leonard, MD) were cut from 5-week-old tomato plants from the same leaf position (third down from apex) grown in a growth chamber at $28^{\circ} \mathrm{C}$ with a 14 -h photoperiod (52). Leaflets were immediately distributed, two per plate, among three 90-mmdiameter petri plates containing a thin layer of $10 \%$ water agar. For each $P$. infestans isolate, five of the leaflets were each inoculated with one $10-\mu 1$ droplet of the inoculum suspension placed on the midvein of the leaf. The sixth leaflet was inoculated with a $10-\mu l$ droplet of sterile distilled water as a negative control. Six sets of three petri dishes were prepared for each isolate and one set each was incubated at $12,16,20$, and $24^{\circ} \mathrm{C}$. The remaining two sets of petri dishes were incubated at $20^{\circ} \mathrm{C}$ for 2 days, after which they were moved to 8 and $28^{\circ} \mathrm{C}$, because preliminary experiments showed that very little infection occurred at the two temperature extremes. Separate identical incubators (Percival Scientific Inc., Perry IA) without lighting were used for each temperature setting. At $0,5,7,9,12$, and 14 days after inoculation (dai), lesion length,

TABLE 1. Characteristics of the Phytophthora infestans isolates used in this study

\begin{tabular}{|c|c|c|c|c|c|c|c|}
\hline Clonal lineage & Isolate & Year & Host & Plant part & County & Mating type & Mefenoxam sensitivity \\
\hline \multirow[t]{5}{*}{ US-22 } & Pi7-09a & 2009 & Tomato & Fruit & Dane & $\mathrm{A} 2$ & Sensitive \\
\hline & Pi14-09a & 2009 & Potato & Tuber & Langlade & A2 & Sensitive \\
\hline & Pil5-10a & 2010 & Potato & Leaf & Marquette & $\mathrm{A} 2$ & Sensitive \\
\hline & Pi23-10a & 2010 & Tomato & Leaf & Vernon & $\mathrm{A} 2$ & Sensitive \\
\hline & Pi29-10a & 2010 & Tomato & Leaf & Manitowoc & $\mathrm{A} 2$ & Sensitive \\
\hline \multirow[t]{5}{*}{ US-23 } & Pi1-09a & 2009 & Potato & Leaf & Vernon & A1 & Sensitive \\
\hline & Pi16-10a & 2010 & Tomato & Fruit & Waukesha & A1 & Intermediate \\
\hline & Pi30-10a & 2010 & Tomato & Fruit & Ozaukee & A1 & Intermediate \\
\hline & Pi35.2-11a & 2011 & Tomato & Leaf & Waukesha & A1 & Intermediate \\
\hline & Pi36.2-11a & 2011 & Potato & Leaf & Adams & A1 & Intermediate \\
\hline \multirow[t]{5}{*}{ US-24 } & Pi21-10a & 2010 & Potato & Leaf & Waushara & A1 & Intermediate \\
\hline & Pi27-10a & 2010 & Potato & Leaf & Portage & A1 & Intermediate \\
\hline & Pi34-10a & 2010 & Potato & Tuber & Portage & A1 & Intermediate \\
\hline & Pi38.1-11a & 2011 & Potato & Leaf & Adams & A1 & Intermediate \\
\hline & Pi40.1-11a & 2011 & Potato & Tuber & Waushara & A1 & Intermediate \\
\hline
\end{tabular}

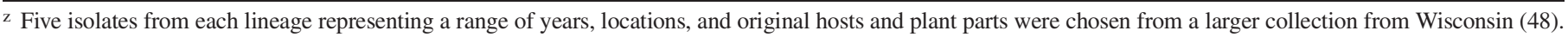


defined as the farthest extent of either mycelial or sporangial growth, or necrotic or chlorotic leaf tissue along the midvein, was measured using a ruler. The experiment was performed twice for each isolate.

Temperature effect on colony growth on rye A agar. Two 8-mm-diameter plugs of mycelia/sporangia from an actively growing 2-week-old $P$. infestans culture were placed in the center of two separate petri dishes containing $17 \mathrm{ml}$ of rye A agar (11). For each isolate, eight separate sets of two plates each were prepared and placed in dark incubators at $4,8,12,16,18,20,24$, and $28^{\circ} \mathrm{C}$. All temperature experiments were performed in identical incubators (Percival Scientific Inc.) except for the $4{ }^{\circ} \mathrm{C}$ temperature treatment, for which a refrigerator equipped with a Ranco electronic temperature control (Medford, MA) was used. Colony diameter was measured at $3,5,7,10,12$, and 14 dai using a ruler. The experiment was performed twice for each isolate.

Sporangia quantification. Inoculum was prepared from $P$. infestans isolates grown on rye A agar as outlined for the lesion growth-rate assay. Tomato plants (Brandywine Red) were grown in a $28^{\circ} \mathrm{C}$ growth chamber with a 14 -h photoperiod. Potato plants ('Katahdin') were grown from cuttings in a greenhouse with a daytime temperature of 18 to $21^{\circ} \mathrm{C}$ and a nighttime temperature of 21 to $24^{\circ} \mathrm{C}$ in an 18 -h photoperiod. Fully expanded leaflets were detached from the third leaf position from the apex of 5-week-old tomato and potato plants, and 15-mm-diameter leaf disks were cut from along the midvein of each leaf using a cork borer (52). Leaf disks (nine each of tomato and potato) were placed in separate 90-mm-diameter petri dishes directly on a thin layer of water agar, and eight of the leaf disks for each species were inoculated with a $10-\mu 1$ droplet of the inoculum suspension prepared as outlined above. The ninth leaf disk was inoculated with a 10- $\mu$ l droplet of sterile distilled water as a negative control. To inhibit excessive drying of the agar and plant tissues while still allowing air flow, unwrapped plates were placed in nonsealing boxes before being placed in a $20^{\circ} \mathrm{C}$ incubator with a 12 -h photoperiod. After 9 days, four sporulating leaf disks were removed from each plate and placed in separate 25-ml plastic centrifuge tubes containing $2 \mathrm{ml}$ of sterile distilled water and 1 drop (12 to $18 \mu \mathrm{l}$ ) of Tween 20 (Agdia Inc., Elkhart, IN). The Tween 20 was necessary to break the surface tension of water around plant trichomes and reduce the variability of sporangial detachment (50). Each suspension was agitated with a vortex and quantified within $1 \mathrm{~h}$ using a hemacytometer. The experiment was performed twice for each isolate and data were analyzed using a two-way analysis of variance (ANOVA), setting clonal lineage and host as factors. Tukey's test at the $95 \%$ level of confidence was used to determine significant differences between clonal lineages and hosts (47).

Measurement of sporangial sizes. Sporangia were harvested from 3-week-old cultures using the method described previously for inoculum preparation. Drops of the suspension were placed on a microscope slide under a cover slip. Photographs were taken of sporangia at $\times 200$ magnification using a Zeiss Axio Scope.A1 microscope (Göttingen, Germany) equipped with a Zeiss AxioCam MRc camera and the AxioVision Release 4.8 software included with the camera. The camera software measurement tool was used to determine length and width of 50 sporangia of each isolate. As a summary statistic, the three-dimensional volume of each sporangium was calculated, assuming that each sporganium was a prolate spheroid, using the standard equation for the volume of this shape: Volume $=(4 / 3) \times \pi \times A \times B^{2}$, where $A$ is half of the major axis and $\mathrm{B}$ is half of the minor axis. Results were analyzed using a oneway ANOVA.

Estimating relative and maximum LGR. Linear models were used to fit lesion growth as a function of time for the experiments conducted at different temperatures on tomato leaflets. Slopes were fit for each isolate and experimental replicate and the slopes of the linear models were used to represent the LGR. The relative LGR (rLGR) were then calculated for each clonal lineage by dividing the LGR (slopes) by the maximum calculated LGR. The rLGR estimates were then plotted versus temperature, and linear (polynomial) regression was used to model relative lesion growth as a function of temperature for each clonal lineage. All analyses were conducted in R, version 2.9.2 (47). The polynomials generated for each lineage were used in the model for rLGR when the temperature was greater than 0 but less than $28^{\circ} \mathrm{C}$. For temperatures over $28^{\circ} \mathrm{C}$, an equation for a line of constant slope between the $y$ value of the curve at $x=28$ and 32.9 was used. The value of 32.94 was the maximum growth temperature value provided in the model.

The maximum LGR of a specific combination of isolate and host was calculated using data from the LGR temperature experiment at $16^{\circ} \mathrm{C}$. For each isolate, the lesion radius at 9 dai (in meters) was divided by the difference between the infection period, defined as the first appearance of necrotic spots, and 9 days to obtain a value for the LGR expressed in meters per day (4). According to the rLGR curves calculated above, the temperature of $16^{\circ} \mathrm{C}$ was not optimal for growth for all lineages. To obtain an estimate of the LGR at the temperature where optimal growth occurs, the polynomial fit for the rLGR was solved at temperature $=16^{\circ} \mathrm{C}$ and the mean of the growth rate for each lineage at $16^{\circ} \mathrm{C}$ divided by the result.

Estimating SR. To prepare the sporangial production data for use in the LATEBLIGHT simulation model, the counts from each leaf disk were averaged to obtain the number of sporangia produced per leaf disk, and number of sporangia per square meter of leaf area was calculated using the equation concentration of sporangia in suspension per area of the leaf disk. An average value for each lineage was calculated from the five isolates of each lineage tested. A latent period of more than 2 days has been observed at $20^{\circ} \mathrm{C}$ for isolates of the US-22, US-23, and US-24 lineages (unpublished data); therefore, the latent period was estimated at a conservative value of 2.5 days. The average sporulation values for each lineage were divided by 6.5 ( 9 days total minus a latent period of 2.5 ) to obtain a value for sporangia production per square meter per day. The parameter SR is the maximum SR for a particular clonal lineage-host interaction. The sporulation experiment was performed at $20^{\circ} \mathrm{C}$, which, according to the relative SR curve provided in the LATEBLIGHT model (4), is greater than the optimal temperature. To obtain the maximum SR, the equation was solved for temperature $=20^{\circ} \mathrm{C}$ and the mean SR per day for each clonal lineage and host divided by the result.

Weather data for the LATEBLIGHT model. Integrated surface weather data for the 2009 to 2012 growing seasons were downloaded from the National Oceanic Atmospheric Association integrated surface database of hourly weather data (ftp://ftp.ncdc. noaa.gov/pub/data/noaa/isd-lite/). Due to its close proximity to the potato-growing region of Wisconsin, data from the Stevens Point, WI weather station (USAF-WBAN Station ID: 726426-04895) were selected to be entered into the LATEBLIGHT model. These weather data include hourly observations of temperature, precipitation, and dew point temperature. The downloaded weather data were arranged as needed for input into the LATEBLIGHT program and, when observations were missing from the data file, linear interpolation using the na.approx function in the zoo package of $\mathrm{R}$ was used to provide an estimate for the missing data (54). Altogether, fewer than $2.3 \%$ observations were missing from the four weather data files. Relative humidity value was calculated from the observed dewpoint temperature and temperature as follows: relative humidity $=100 \times(\exp [(17.625 \times \mathrm{DP}) /(243.04+\mathrm{DP})]) /(\exp$ $[(17.625 \times \mathrm{T}) /(243.04+\mathrm{T})])$, where DP is the dewpoint temperature and $\mathrm{T}$ is the temperature.

LATEBLIGHT simulation. The LATEBLIGHT simulation model was downloaded from the CIP website (https://research.cip. cgiar.org/confluence/display/GILBWEB/Download+LATEBLIGHT+ Simulator) and set up and run using SAS (version 9.4; SAS Institute Inc., Cary, NC) according to the instructions provided. For each year, the weather data were input and the EmergDate parameter in the file "Estimating initial inoculum" was set to reflect the date of 
$50 \%$ emergence of midplanted potato for the Stevens Point, WI area for each year (Table 2). The threshold for relative humidity was set to $85 \%$ according to the instructions for the simulation, because the weather data were collected from outside of the plant canopy. Initial inoculum was estimated following the instructions provided in the "Estimating initial inoculum" file. Commercial fields are typically scouted every week; therefore, the last day that no lesions were seen ( $\mathrm{t} 0$ date) was set to 7 days before first day that lesions were detected (Table 2). An exception was in 2009, where the t0 date was set earlier due to the known likelihood that late blight was introduced on tomato transplants much earlier than the date the disease was actually recognized (48). The cultivar used was set to a susceptible longseason cultivar and the fungicide program was set as "no fungicides."

For each year of weather data (2009 to 2012), the epidemic was run with the default pathogen parameters provided in the downloaded version, which are based mostly on the EC-1 clonal lineage, where SR was 292,000,000 and LGR was 0.00410; and the equations and domains for rLGR were set as in the work of Andrade-Piedra et al. (4). In subsequent simulations, the SR or LGR and rLGR were changed to reflect the new sporulation and growth rates obtained for each clonal lineage in the experiments outlined above. For example, the SR parameter and the LGR parameters (LGR and rLGR) for US-22 on tomato were first changed separately to examine the effect of changing either the SR or LGR on epidemic progression. The SR and LGR parameters were then changed in combination to further examine the effect of changing both sporulation and lesion growth on epidemic progression. Because LGR parameters were not measured on potato, only the effect of SR was examined for the clonal lineage/potato combination. All other parameters in the model were set to the default values. Epidemic simulations were run and disease severity data were output and concatenated in R, version 2.9.2 (47), which was used to calculate severity (AUDPC), epidemic length (EL), and rate of progression (apparent infection rate $[\mathrm{AIR}]$ ) of each simulated epidemic to be used for comparison.

\section{RESULTS}

Growth rate assays. A cubic polynomial model was fitted to the average relative growth rate of five isolates from each clonal lineage. The overall $F$ tests for the model fits were as follows: rye A-US-22 $\left(F=80.0 ;\right.$ df $=3,36 ; P<0.0001 ;$ Adj-R $\left.{ }^{2}=0.89\right)$, rye A-US-23 $\left(F=209.6 ; \mathrm{df}=3,36 ; P<0.0001 ;\right.$ Adj-R $\left.{ }^{2}=0.94\right)$, rye A-US-24 $\left(F=54.0 ; \mathrm{df}=3,36 ; P<0.0001 ;\right.$ Adj-R $\left.^{2}=0.80\right)$, tomato leaf-US-22 $\left(F=8.3 ; \mathrm{df}=3,26 ; P<0.001 ;\right.$ Adj-R $\left.{ }^{2}=0.43\right)$, tomato leaf-US-23 $\left(F=20.6 ; \mathrm{df}=3,26 ; P<0.0001 ;\right.$ Adj-R $\left.{ }^{2}=0.67\right)$, and tomato leaf-US-24 $\left(F=4.5 ; \mathrm{df}=3,26 ; P=0.012 ; \mathrm{Adj}^{-\mathrm{R}^{2}}=\right.$ 0.26 ). Pathogen growth on rye A agar was different from growth on tomato leaves. Most notably, the relative growth rate on agar

TABLE 2. Parameters input for the LATEBLIGHT simulations for each epidemic year

\begin{tabular}{lcllc}
\hline Year & $\begin{array}{c}\text { Emergence } \\
\text { date }^{\mathrm{w}}\end{array}$ & $\begin{array}{c}\text { First late } \\
\text { blight } \\
\text { observed }^{\mathrm{x}}\end{array}$ & $\begin{array}{c}\text { Estimated } \\
\text { inoculation } \\
\text { date }^{\mathrm{y}}\end{array}$ & $\begin{array}{c}\text { Estimated } \\
\text { initial } \\
\text { inoculum }^{\mathrm{z}}\end{array}$ \\
\hline 2009 & 20 May & 29 July & 10 July & 4 \\
2010 & 18 May & 14 July & 9 July & 5 \\
2011 & 20 May & 25 August & 20 August & 5 \\
2012 & 10 May & 31 July & 26 July & 5 \\
\hline
\end{tabular}

${ }^{\mathrm{w}}$ Dates for $50 \%$ emergence of potato for the Stevens Point, WI area.

$\times$ Date that late blight was first observed by growers or crop consultants in or near the central sands area of Wisconsin. Identity of Phytophthora infestans as the causal agent of the disease was confirmed based on testing of samples submitted to our lab.

y Inoculation date as defined and estimated by the program "Estimating initial inoculum" included with the LATEBLIGHT simulation.

${ }^{\mathrm{z}}$ Initial microcolonies as defined and estimated by the program "Estimating initial inoculum" included with the LATEBLIGHT simulation. declined to nearly zero at $28^{\circ} \mathrm{C}$, particularly for the US-23 (0.0619) and US-24 (0.0706) isolates (Fig. 1). In contrast, tomato rLGR were high at $28^{\circ} \mathrm{C}$ after the $20^{\circ} \mathrm{C}$ establishment period of 2 days, particularly for the US-22 (0.759) and US-23 (0.745) isolates, with growth only slightly less than that at the optimum temperature (difference $\leq 0.163$ ) (Fig. 1). Differences in temperature optima between experiments on rye A agar and experiments on tomato leaves were also apparent. Based on the growth curves, the optimal temperatures on rye A agar were $19.5,19.9$, and $19.9^{\circ} \mathrm{C}$ for the US22, US-23, and US-24 isolates, respectively. On tomato leaves, the optimal temperatures for lesion expansion were 15.8, 21.5, and $16.2^{\circ} \mathrm{C}$ for the US-22, US-23, and US-24 isolates, respectively.

Because the relationship of the rLGR to temperature was not linear, predicted values for rLGR ( \pm standard error $[\mathrm{SE}]$ ) were obtained from the fitted cubic polynomials over the temperature range of the experiments, and $95 \%$ confidence intervals were estimated around the rLGR predictions. The rLGR for isolates of the US-23 and US-24 clonal lineages were not different at any temperature and demonstrated little growth on rye A agar at 4 and $28^{\circ} \mathrm{C}$, with some isolates demonstrating no growth (Fig. 1). Similarly, the rLGR for isolates of the US-22 clonal lineage were not different from those of the US-24 isolates. However, the rLGR of isolates representing the US-22 clonal lineage were significantly greater than those calculated for isolates of the US-23 clonal lineage at temperatures less than $16.8^{\circ} \mathrm{C}$ and greater than $26.5^{\circ} \mathrm{C}$. (Fig. 1).

On tomato leaves, the rLGR of US-22 and US-23 isolates were not different at any temperature (Fig. 1). However, the rLGR for US-22 were significantly greater than the rLGR for US-24 at temperatures greater than $25.2^{\circ} \mathrm{C}$. Similarly, the rLGR for US-23 were significantly greater than the predicted rLGR for US-24 at temperatures greater than $20.7^{\circ} \mathrm{C}$. Overall, the mean LGR $\left(\times 10^{-3} \mathrm{~m} /\right.$ day $)$ on tomato leaves were greatest for isolates of the US-22 and US-23 lineages at $4.8(\mathrm{SE}=0.8)$ and $4.7(\mathrm{SE}=0.7)$, respectively, which were significantly different by pairwise $t$ test $(P=0.1)$ from the LGR of isolates of the US-24 lineage at $2.5(\mathrm{SE}=$ $0.5)$. Estimates of the maximum LGR, the mean LGR corrected growth occurring at the temperature optimum of each clonal lineage, were calculated for input into the LATEBLIGHT model (Table 3).

Sporangia quantification. There was no significant difference between the two repetitions of the experiment $(P=0.466)$; therefore, the data were pooled prior to conducting a two-way ANOVA using clonal lineage and host as factors. One isolate each from the US-22 and US-24 clonal lineages failed to infect or sporulate on either potato or tomato leaves; therefore, the analysis was performed on the remaining four isolates for each of these lineages. For all of the isolates representing clonal lineages, there were always significantly fewer sporangia produced per square meter per day on tomato than on potato $(P<0.001)$; however, the greatest difference between the two hosts occurred when inoculated with the isolates representing the US-24 clonal lineage of $P$. infestans, with a difference between means of $1.15 \times 10^{8}$ (Fig. 2). On tomato, the US-23 isolates produced significantly more sporangia than the US-22 $(P=0.001)$ and US-24 isolates $(P<0.001)$ (Fig. 2$)$. On potato, sporulation by the US-23 isolates was also high but not significantly different from that by the US-24 isolates on potato $(P=0.455)$ (Fig. 2).

Sporangial size. Sporangia from isolates of the US-22 and US23 clonal lineages were similar in size and significantly smaller than sporangia from isolates of the US-24 clonal lineage $(P<0.001$ for both comparisons) based on the calculated volume of each sporangium. Sporangia of isolates of the US-22 and US-23 clonal lineages had mean volumes of $4,677 \mu \mathrm{m}^{3}$ (standard deviation [SD] = $2,137)$ and $4,916 \mu \mathrm{m}^{3}(\mathrm{SD}=2,442)$, respectively, while those of the US-24 isolates had a volume of $6,352 \mu \mathrm{m}^{3}(\mathrm{SD}=2,330)$.

Wisconsin weather data. In Wisconsin, late blight occurred in every year from 2009 to 2012 despite weather variation. The 2009 growing season was characterized by temperatures mostly below 
the 30-year average and moderate rainfall (Fig. 3). The 2010 growing season had average temperatures but abnormally high rainfall amounts, particularly during mid- to late summer (Fig. 3). The 2011 growing season was characterized by slightly aboveaverage temperatures and moderate rainfall (Fig. 3). The 2012 growing season had many abnormally high temperatures, particularly in the beginning of the season, and very little rainfall, particularly in the middle of the growing season (Fig. 3). These differences in seasonal weather were reflected in the number of hours that the relative humidity was above $85 \%$ in each year, an important consideration for $P$. infestans growth and referred to as HumidHrs in the LATEBLIGHT simulation model (Fig. 3). The year 2010 accumulated the most HumidHrs, followed closely by 2011 and then 2009 (Fig. 3). The year 2012 accumulated many fewer HumidHrs than the other years (Fig. 3).

LATEBLIGHT simulation modeling. When epidemics were simulated using the default pathogen parameters included in the model distribution and based on the EC-1 clonal lineage (4), AUDPC values were greatest in 2010 and least in 2011 and reached $100 \%$ severity in all years except 2011 (Table 4; Fig. 4). Rates of
TABLE 3. Values of lesion growth rate (LGR; meters per day) and sporulation rate (SR; sporangia per square meter per day) used in the LATEBLIGHT model

\begin{tabular}{lclr}
\hline Parametery $^{\mathrm{y}}$ & Clonal lineage & Host & Maximum $^{\mathrm{z}}$ \\
\hline SR & US-22 & Tomato & $240,547,134$ \\
& & Potato & $319,975,001$ \\
& US-23 & Tomato & $364,123,653$ \\
& US-24 & Potato & $441,660,924$ \\
& Tomato & $172,177,767$ \\
& US-22 & Potato & $398,320,459$ \\
LGR $\left(\times 10^{-3}\right)$ & US-23 & Tomato & 6.33 \\
& US-24 & Tomato & 5.86 \\
& Tomato & 4.01
\end{tabular}

y SR were determined using a leaf disk assay conducted in a moist chamber at $20^{\circ} \mathrm{C}$ with a 12 -h photoperiod. LGR were determined using a detached leaf assay conducted in a moist chamber at $16^{\circ} \mathrm{C}$ without light.

${ }^{\mathrm{z}}$ Equation that relates the relative SR to temperature (4) was used to adjust the mean SR at $20^{\circ} \mathrm{C}$ to obtain the maximum SR, which occurs at approximately $14^{\circ} \mathrm{C}$. Similarly, the equation that relates the relative LGR to temperature was used to adjust the mean LGR obtained at $16^{\circ} \mathrm{C}$ to the maximum LGR for isolates of each clonal lineage.

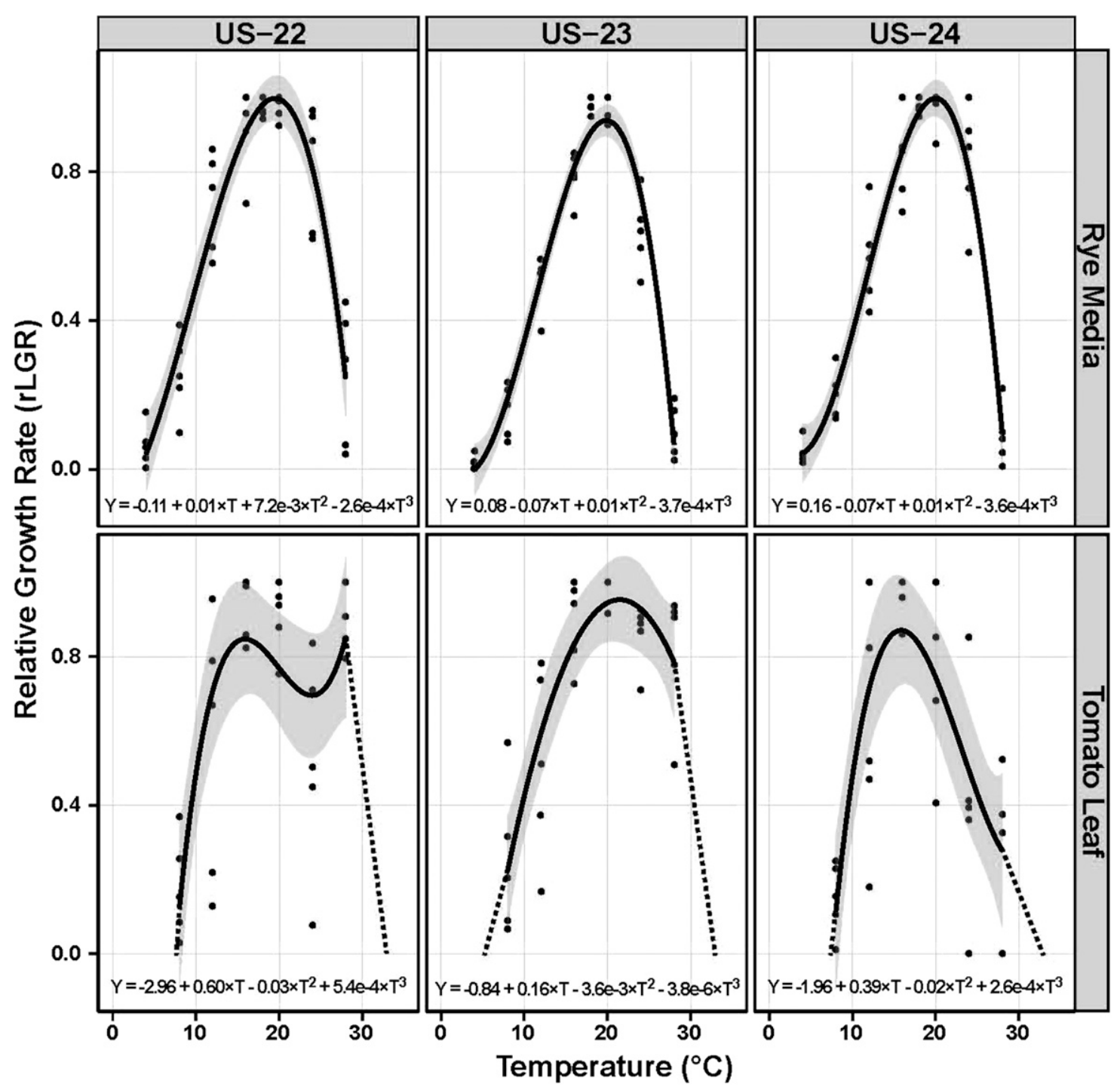

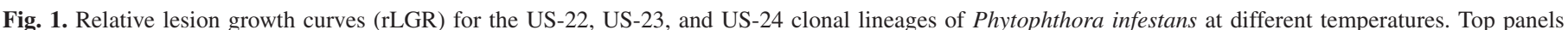

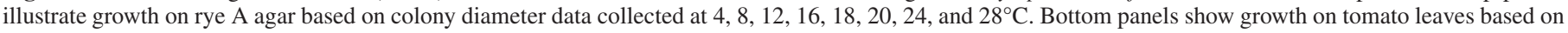

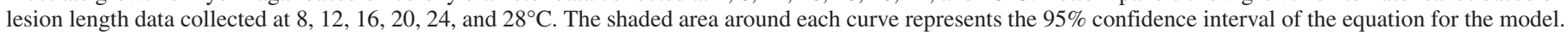

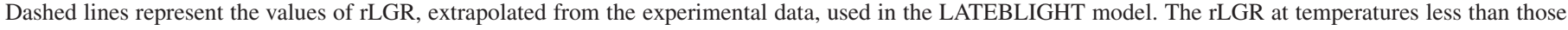

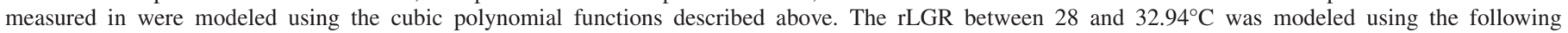

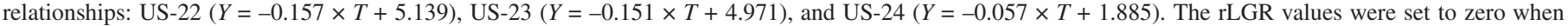
environmental conditions resulted in negative rLGR estimates. 


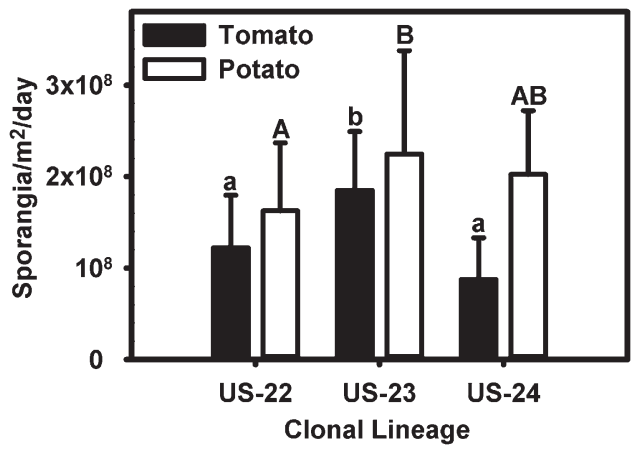

Fig. 2. Sporulation rate of the US-22, US-23, and US-24 clonal lineages of Phytophthora infestans on tomato and potato at $20^{\circ} \mathrm{C}$. Bars represent the mean of four or five isolates of each clonal lineage and error bars depict the standard error. Sporulation rates of isolates of each clonal lineage were statistically higher for potato than tomato. Different letters over the bars indicate significant differences between the clonal lineages for each host (lowercase for tomato and uppercase for potato). Tukey's honest significant difference test (confidence level $=0.95$ ) was used to determine differences among treatment means. epidemic progression were greatest in 2010 followed by 2009, 2012, and 2011, and EL were usually inversely related to the AIR (Table 4). Among years, AUDPC and AIR values of the simulated epidemics for isolates of the US-22, US-23, and US-24 clonal lineages tracked the AUDPC and AIR for epidemics simulated for the EC-1 clonal lineage. Also, percent change of AUDPC relative to the AUDPC the default model settings was always similar to the percent change of AIR relative to the AIR of the default model settings (Table 5). The greatest difference in measures of epidemic progression and severity for isolates of the US-22, US-23, and US24 clonal lineages relative to the simulated epidemics of the EC-1 clonal lineage usually occurred in 2011. When measures of epidemic progression and severity for isolates of each clonal lineage were averaged over all of the years, isolates of the US-23 had the greatest increase $(\mathrm{AUDPC}=21.0 \%, \mathrm{AIR}=21.6 \%$ ) relative to the EC-1 default across all simulated epidemics (Table 5). Isolates of the US-22 lineage averaged over all of the years had slightly higher AUDPC values than the default (3.6\%), while those for US-24 were lower $(-32.5 \%)$. Among all simulated epidemics, adjusting the SR to reflect the SR we determined for P. infestans
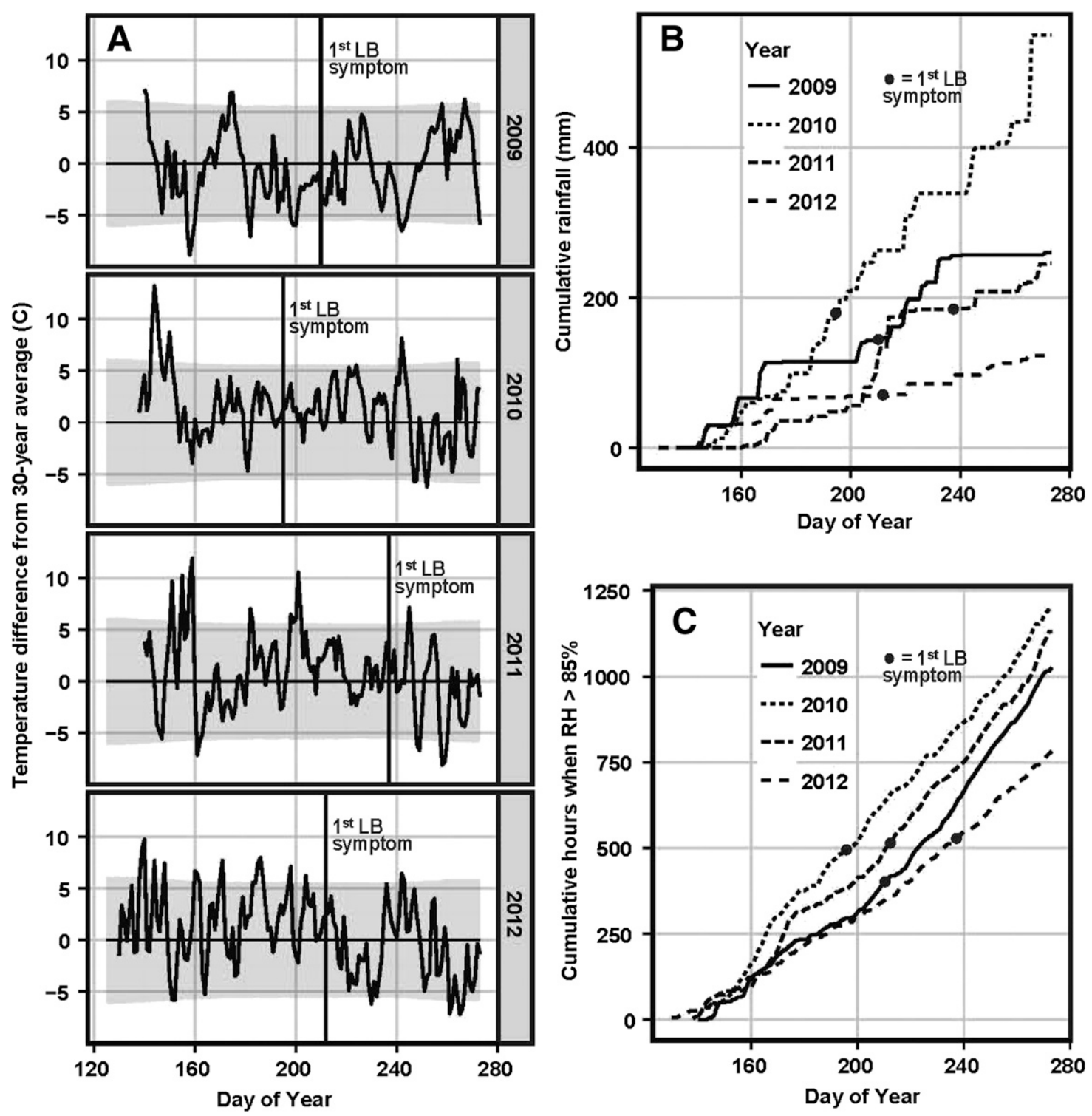

Fig. 3. A, Deviation of the average daily temperatures from the 30-year average at Stevens Point, WI for each growing season (2009 to 2012). The shaded area in each panel represents the range for the 30-year average high and low temperatures. The bold vertical line in each plot demarks the date on which late blight symptoms were first observed. B, Cumulative rainfall and C, cumulative hours when relative humidity was above $85 \%$ for each growing season (2009 to 2012 ). Points on each line demark the date on which late blight symptoms were first observed. 
isolates on potato always resulted in an increase in the AUDPC or AIR values relative to the default model settings.

For the US-22 clonal lineage, changing the SR to be a value consistent with our measurements of sporulation on tomato decreased the AUDPC relative to the default epidemic but adjusting SR to be consistent with our measurements of sporulation on potato always increased the AUDPC (Table 5; Fig. 4). Changing the LGR parameters (rLGR and maximum LGR) to reflect our lesion growth measurements of isolates of the US-22 lineage increased the AUDPC in every year except in 2010, where it had no effect on AUDPC. For isolates of US-22, changing the LGR parameters had a greater effect on increasing the AUDPC than changing the SR to be consistent with our measurement of sporulation on potato. For example, AUDPC for epidemic simulations of US-22 were, on average, $15.4 \%$ more severe than the default EC-1 clonal lineage when the LGR parameters changed to be consistent with our measurements of lesion growth (Table 5; Fig. 4). However, when both the SR and the LGR parameters were changed simultaneously for the US-22 lineage, the AUDPC was only, on average, 3.0\% greater than the simulated epidemics of the EC-1 clonal lineage. Thus, changing the SR attenuated the effect of changing the LGR on the simulated AUDPC for US-22 clonal lineages. When AIR was used as the epidemic descriptor, adjusting the model parameters resulted in response patterns that were similar to those when AUDPC was used to describe the epidemic (Table 5).

Unlike the US-22 and US-24 clonal lineages, all the simulated epidemics for isolates of the US-23 clonal lineage progressed more quickly and were more severe relative to the EC-1 default model settings. Changing the LGR parameters (rLGR and maximum LGR) to be consistent with the measured (LGR) rates for isolates of the US-23 lineage led to a $26.9 \%$ increase in AUDPC relative to the default AUDPC. Changing the LGR had a greater effect on AUDPC than changing the SR parameter, which led to AUDPC increases of only 16.1 and $8.2 \%$ for rates consistent with the SR observed on potato and tomato, respectively (Table 5). Changing the LGR parameters coincidently with the SR parameters caused, on average, a $32.7 \%$ increase in AUDPC and a $42.0 \%$ increase in the AIR (Table 5). Among years, the increase in epidemic severity was most evident in 2011, when AUDPC and AIR were 87.8 and $106.3 \%$ higher for simulated epidemics of US-23 isolates, respectively, relative to the default model settings.

For isolates of the US-24 clonal lineage, all changes to the model parameters to make them consistent with our experimental measurements resulted in reduced AUDPC and AIR values relative to the default, except for changes to the SR as measured on potato
(Tables 4 and 5). In all years, changing the LGR parameters reduced the simulated AUDPC and AIR values more than changing the SR parameter to reflect sporulation on tomato (Table 4). The effects of lesion growth and SR were not additive but, when both parameters were simultaneously changed to reflect our experimental measurements, epidemics progressed slowly, with AUDPC values as low as 90 in 2011 (Table 4). For isolates of the US-24 clonal lineage, simulated epidemics only reached $100 \%$ severity in 2009 and in all years when only the SR as measured for potato was changed (Table 4). Simulated epidemics for isolates of the US-24 clonal lineage progressed more slowly $(-28.3 \%)$ and were less severe $(-32.5 \%)$ than simulated epidemics for the EC-1 default (Table 5).

\section{DISCUSSION}

Subtle changes in biological characteristics, such as sporangial size and quantity produced or optimal temperatures for lesion expansion, are difficult to quantify in a field setting. Simulation modeling can provide insight into the effect of biological changes in the pathogen population. In the current study, isolates of $P$. infestans representing the genotype of US-23 had the highest SR on both potato and tomato leaves; US-22 readily infected both potato and tomato but total sporulation by this lineage was less than US-23, and the US-24 lineage, while having a high SR on potato, had the lowest $\mathrm{SR}$ of the lineages tested on tomato. When parameters in the LATEBLIGHT model were modified to reflect the experimentally determined LGR and SR of the three lineages, simulated epidemics for representative isolates of the US-23 clonal lineage consistently progressed at a higher rate and were more severe than the simulated epidemics of isolates of either the US-22, US-24, or EC-1 (default) clonal lineages, regardless of environmental conditions. The rate of progression and severity of the simulated epidemics on both potato and tomato suggest that the US-23 genotype has the greatest epidemic potential when compared with US-22 and US-24 and, thus, was likely to be abundant in the pathogen population. Indeed, this has been observed in Wisconsin and across the United States in the past several years. In Wisconsin, the US-23 lineage first appeared in a single location in 2009 (49). Over the following 3 years, the proportion of late blight samples collected that yielded the US-23 lineage steadily increased and the relative abundance of the US-22 and US-24 lineages decreased until 2012. Since that time, US-23 has been the primary lineage identified (49). Similarly, across the United States, US-22 was the predominant lineage reported in 2009 but, by 2013, almost all of the reports of late blight were caused by US-23 (6).

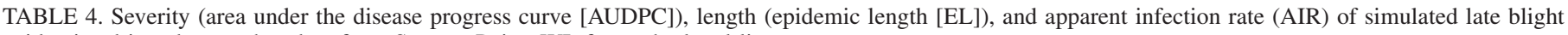
epidemics driven by weather data from Stevens Point, WI, for each clonal lineagey

\begin{tabular}{|c|c|c|c|c|c|c|c|c|c|c|c|c|c|}
\hline \multirow[b]{2}{*}{ Clonal lineage } & \multirow[b]{2}{*}{ Adjusted parameter ${ }^{\mathrm{z}}$} & \multicolumn{3}{|c|}{2009} & \multicolumn{3}{|c|}{2010} & \multicolumn{3}{|c|}{2011} & \multicolumn{3}{|c|}{2012} \\
\hline & & AUDPC & EL & AIR & AUDPC & EL & AIR & AUDPC & EL & AIR & AUDPC & EL & AIR \\
\hline Default & & 5039 & 26 & 0.394 & 5796 & 25 & 0.445 & 1067 & - & 0.276 & 3335 & 36 & 0.284 \\
\hline \multirow[t]{4}{*}{ US-22 } & SR potato & 5092 & 25 & 0.394 & 5850 & 24 & 0.468 & 1166 & - & 0.284 & 3405 & 35 & 0.286 \\
\hline & SR tomato & 4923 & 27 & 0.368 & 5639 & 32 & 0.385 & 872 & - & 0.261 & 3140 & 44 & 0.257 \\
\hline & LGR & 5297 & 27 & 0.388 & 5797 & 25 & 0.448 & 1592 & 30 & 0.390 & 3580 & 36 & 0.291 \\
\hline & $\mathrm{SR}+\mathrm{LGR}$ & 5172 & 29 & 0.375 & 5646 & 31 & 0.391 & 1171 & - & 0.296 & 3412 & 38 & 0.279 \\
\hline \multirow[t]{4}{*}{ US-23 } & SR potato & 5272 & 23 & 0.424 & 6004 & 21 & 0.495 & 1561 & - & 0.339 & 3660 & 33 & 0.307 \\
\hline & SR tomato & 5163 & 24 & 0.402 & 5915 & 23 & 0.492 & 1314 & - & 0.298 & 3507 & 34 & 0.295 \\
\hline & LGR & 5495 & 26 & 0.419 & 6108 & 21 & 0.487 & 1871 & 23 & 0.480 & 3936 & 35 & 0.320 \\
\hline & $\mathrm{SR}+\mathrm{LGR}$ & 5631 & 24 & 0.462 & 6200 & 20 & 0.522 & 2004 & 19 & 0.568 & 4144 & 33 & 0.360 \\
\hline \multirow[t]{4}{*}{ US-24 } & SR potato & 5214 & 24 & 0.422 & 5958 & 22 & 0.490 & 1427 & - & 0.312 & 3576 & 34 & 0.306 \\
\hline & SR tomato & 4675 & 33 & 0.337 & 4720 & - & 0.158 & 584 & - & 0.236 & 2558 & - & 0.184 \\
\hline & LGR & 3892 & 39 & 0.257 & 2972 & - & 0.124 & 257 & - & 0.226 & 1603 & - & 0.172 \\
\hline & $\mathrm{SR}+\mathrm{LGR}$ & 3254 & 45 & 0.229 & 1967 & - & 0.121 & 90 & - & 0.187 & 655 & - & 0.137 \\
\hline
\end{tabular}

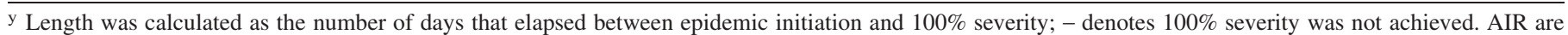
reported as the slope the simple linear regression of logit-transformed severity values versus time.

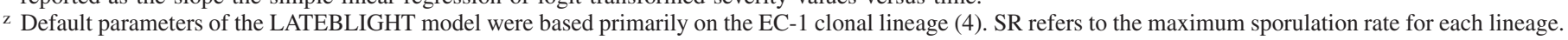
LGR refers to the maximum lesion growth rate and relative lesion growth rate as a function of temperature for a clonal lineage. SR + LGR designates that both SR and LGR were changed for the simulated epidemic. 
As noted above, new genotypes occasionally replace established genotypes quickly. A hypothetical reason for this may be competition between genotypes differing in fitness. If it is assumed that biotypes are part of a common population with similar survival potential and limiting resource (susceptible plants), then the apparent infection rate may be viewed as a correlate of their fitness $(7,32)$. It would be expected that a genotype with a higher infection rate would displace one with a lower infection rate. As a first approximation, the ratio of infection rates can be used as a measure of the relative fitness to calculate the changes in frequency of each genotype over pathogen generations (33). For example, the infection rates accounting for both SR and LGR from the simulations of US-22 and US-23 in 2011 were 0.296 and 0.568 , respectively (Table 4). Assuming both genotypes were present in equal amounts initially, US-23 would constitute $99.8 \%$ of the population in 10 generations. Using the average infection rate over the 4 years of this study for US-22 and US-23 results in US-23 constituting 97\% of the population after 10 generations. Although direct competition probably does not occur in many cases, this calculation illustrates the significant differences in fitness between these genotypes and may help explain the occasional sudden change in predominant genotypes.

The AIR and AUDPC were calculated for each simulated epidemic and, in general, the AUDPC values were influenced more by the length of the simulated epidemic than AIR values. This is likely due to the number of days a simulated epidemic was at $100 \%$ severity and was influenced by the inoculation date of the simulated epidemic rather than environmental conditions. For example, the rank of inoculation date was nearly perfectly correlated with the AUDPC rank for the simulated epidemics $(R=0.97)$ while the correlation between inoculation date rank and AIR rank was lower $(R=0.46)$. Therefore, we consider the AIR to more accurately reflect the influence of the environment on the pathogen.

An observed increase in the AIR of US-22 and US-23 at warmer temperatures suggests that these lineages may have a fitness advantage at warmer temperatures. The effect of temperature on the AIR for each clonal lineage was most evident when the LGR were

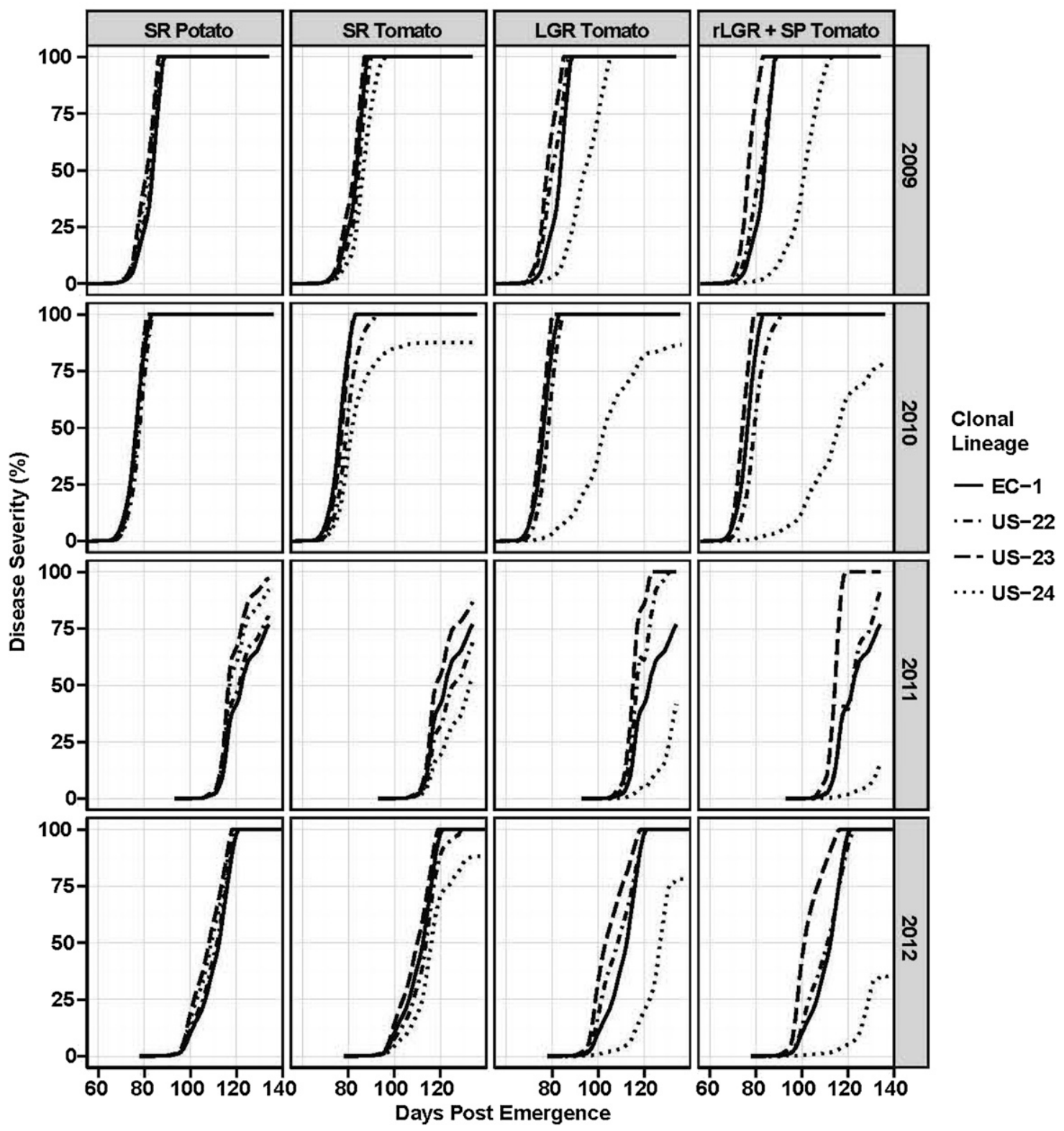

Fig. 4. Results of late blight epidemic simulation using the LATEBLIGHT model (Andrade-Piedra). The parameters of sporulation rate (SR) on potato and tomato and relative lesion growth rate (rLGR) on tomato were changed first separately and then together for the US-22, US-23, and US-24 clonal lineages of Phytophthora infestans for each of 4 years of weather data from Stevens Point, WI. Different line colors indicate the different simulated epidemics produced by each lineage for each combination of modified parameters. 
modified in the LATEBLIGHT model to reflect our experimental results. The maximum LGR determined for the US-22 and US-23 lineages were larger than the LGR of the default EC-1 lineage. US22 and US-23 lineages grew faster at higher temperatures than the EC-1 lineage. For example, the US-23 lineage demonstrated optimal growth at $21^{\circ} \mathrm{C}$, which is nearly $2^{\circ} \mathrm{C}$ greater than the optimal temperature for growth of the EC-1 lineage (4). When temperatures were, on average, cool (i.e., 2009), both the US-22 and US-23 lineages had epidemic progression rates that were equal to the default lineage. However, in 2011, when the average temperature was higher, simulated epidemics of US-22 and US-23 increased at a rate greater than the default. This suggests that the US-22 and US-23 lineages are not negatively affected by cooler conditions and may have a fitness advantage under warmer conditions. The observed increase in the rate of disease progress of the US-22 and US-23 lineages at warmer temperatures suggests that isolates of US-22 and US-23 may thrive in warmer climactic regions or regions that are becoming warmer due to climate change (2).

On rye A agar, the optimal temperature for growth was similar for each clonal lineage. However, on tomato leaves, there was variation among the optimal growth temperatures of the lineages. Optimal growth of the US-22 and US-24 lineages on tomato leaves occurred below the optimal temperatures on rye A agar whereas optimal growth of US-23 on tomato leaves occurred at a temperature above the optimal temperature on rye A agar. Isolates of the US-22 and US-23 lineages had a high rate of growth on tomato leaves and a moderate rate of growth on rye A agar at $28^{\circ} \mathrm{C}$. In several secondary research documents, including a Phytophthora key, the maximum temperature for growth is reported to be $26^{\circ} \mathrm{C}(17,19)$, which is inconsistent with our data.

Differences in the basic biology of the clonal lineages might have gone undetected if rye A was used exclusively. For example, isolates of the US-24 lineage readily grew on rye A media in the laboratory and resembled isolates of US-23 and US-24 with respect to growth but isolates of US-24 did not grow well on tomato leaves. This result is consistent with field observations of the US-24 lineage, which has never been isolated from tomato in Wisconsin (49) and has only seldom been isolated from tomato elsewhere $(13,37)$. Several studies have suggested that US-24 is a poor tomato pathogen $(13,37)$ even though lesions are produced and sporulation can be induced under ideal laboratory conditions. The detached tomato leaf assay more accurately represents a field situation than does the rye A media growth assay.

Currently, the effect of sporangia size on late blight epidemic progression is not known. However, smaller sporangia may be lifted from the leaf surface, escape the plant canopy, and travel farther on air currents more easily than large sporangia. As such, small sporangia may infect fields at a greater distance than large sporangia (8). We found differences in the average sporangial size among isolates of the US-22, US-23, and US-24 lineages, with US-22 and US-23 having the smallest sporangia. If sporangia size is a driver of epidemic progression, then isolates of the US-22 and US-23 lineages would have a selective advantage over isolates of the US24 lineage, which had the largest sporangia. Future revisions of the LATEBLIGHT simulation model could consider sporangia size as a biological factor that influences epidemic progression by attuning the model parameters associated with dispersion and deposition of sporangia.

The LATEBLIGHT simulation model was originally designed for use on potato. Although, historically, US-1 was the only lineage in the United States and was not highly virulent on tomato $(26,28,44)$, many lineages that have been identified in the past 25 years, including those in the present study, are virulent on both potato and tomato (28). Because late blight is easily spread within and among fields, virulence on tomato should not be ignored when considering the overall epidemiology of late blight. Wisconsin has approximately 800 ha of tomato production in addition to 25,000 ha of potato production. To fully understand late blight epidemiology in Wisconsin, it will be necessary to determine how the tomato crop influences epidemic progression. Our initial extension of the LATEBLIGHT model to incorporate tomato as a host used several experimentally determined pathogen growth and sporulation measures to make the model applicable to the tomato crop. Further experimentation is needed to determine whether the potato (model) assumptions are valid or whether new model parameters and equations will be needed to apply the LATEBLIGHT model to tomato.

The simulated epidemics did not closely represent the epidemics that were observed in Wisconsin potato fields. In all years examined, the disease severity of the simulated epidemics was higher than the field-observed disease severity. The lack of correspondence is due to multiple causes but disease management by growers (i.e., fungicide programs) is likely the greatest reason for the lack of agreement between the simulated disease severity and disease severity observed in Wisconsin potato fields. For example, the risk imposed by a sporangia shower may be effectively mitigated for a large proportion of a field that received a prophylactic fungicide application. Yet several plants within the field might lack a protective fungicide, such as plants directly around irrigation stands or in field corners, and become infected, resulting in a single disease focus in the field. In these cases, the unprotected crop around the inoculation point might reach $100 \%$ severity as simulated but represent only a small proportion of the whole field. The lack of correspondence between disease severity observed in potato fields and simulated disease

TABLE 5. Percent change of area under the disease progress (AUDPC) and apparent infection rate (AIR) for simulated epidemics in each year and for each Phytophthora infestans clonal lineage relative to simulated epidemics in each year using the default model parameters (EC-1 clonal lineage) ${ }^{\mathrm{y}}$

\begin{tabular}{|c|c|c|c|c|c|c|c|c|c|c|c|c|c|c|c|}
\hline \multirow[b]{2}{*}{ Adjusted parameter ${ }^{z}$} & \multicolumn{5}{|c|}{ US-22 } & \multicolumn{5}{|c|}{ US-23 } & \multicolumn{5}{|c|}{ US-24 } \\
\hline & 2009 & 2010 & 2011 & 2012 & Mean & 2009 & 2010 & 2011 & 2012 & Mean & 2009 & 2010 & 2011 & 2012 & Mean \\
\hline \multicolumn{16}{|l|}{ AUDPC } \\
\hline SR potato & 1.0 & 0.9 & 9.2 & 2.1 & 3.3 & 4.6 & 3.6 & 46.3 & 9.8 & 16.1 & 3.5 & 2.8 & 33.6 & 7.3 & 11.8 \\
\hline LGR & 5.1 & 0.0 & 49.1 & 7.4 & $15.4 \mathrm{~A}$ & 9.0 & 5.4 & 75.3 & 18.1 & $26.9 \mathrm{~A}$ & -22.8 & -48.7 & -75.9 & -51.9 & $-49.8 \mathrm{~B}$ \\
\hline $\mathrm{SR}+\mathrm{LGR}$ & 2.6 & -2.6 & 9.7 & 2.3 & $3.0 \mathrm{~A}$ & 11.8 & 7.0 & 87.8 & 24.3 & $32.7 \mathrm{~A}$ & -35.4 & -66.1 & -91.5 & -80.4 & $-68.3 \mathrm{~B}$ \\
\hline \multicolumn{16}{|l|}{ AIR } \\
\hline LGR & -1.4 & 0.8 & 41.5 & 2.7 & $10.9 \mathrm{~A}, \mathrm{~B}$ & 6.4 & 9.5 & 74.1 & 12.9 & $25.7 \mathrm{~A}$ & -34.7 & -72.0 & -17.9 & -39.5 & $-41.0 \mathrm{~B}$ \\
\hline $\mathrm{SR}+\mathrm{LGR}$ & -4.8 & -12.1 & 7.5 & -1.6 & $-2.7 \mathrm{~A}, \mathrm{~B}$ & 17.4 & 17.4 & 106.3 & 26.8 & $42.0 \mathrm{~A}$ & -41.8 & -72.9 & -32.1 & -51.9 & $-49.7 \mathrm{~B}$ \\
\hline
\end{tabular}

$\mathrm{y}$ Within a row, means followed by the same letter were not significantly different $(P=0.05)$ by pairwise $t$ test with a Bonferroni correction; means with no following letter were not different by an analysis of variance $(F=0.05)$. Percent change was calculated as $\left[\left(\mathrm{AUDPC}_{\text {Sim }}-\mathrm{AUDPC}_{\text {Default }}\right) / \mathrm{AUDPC}_{\text {Default }}\right] \times 100$ and $\left[\left(\mathrm{AIR}_{\mathrm{Sim}}-\mathrm{AIR}_{\text {Default }}\right) / \mathrm{AIR}_{\text {Default }}\right] \times 10$.

z Default parameters of the LATEBLIGHT model were based primarily on the EC-1 clonal lineage (4). SR refers to the maximum sporulation rate for each lineage. LGR refers to the maximum lesion growth rate and relative lesion growth rate as a function of temperature for a clonal lineage. SR + LGR designates that both SR and LGR were changed for the simulated epidemic. 
severity could also be due to the source of the weather data that was used to simulate the epidemics. In this study, the weather data were collected from weather stations that were not located in the crop canopy. Therefore, the estimation of leaf wetness included precipitation but did not account for overhead irrigation, a practice that is heavily relied upon in central Wisconsin. As a result, the LATEBLIGHT model likely underestimated the hours of leaf wetness, and late blight epidemics may progress faster than those simulated in this work due to the effects of irrigation. To improve the correspondence between simulated epidemic progression and observed epidemic progression, future experiments should consider the effect of fungicide and assess proxies for leaf wetness.

Currently, laboratory assays exist that can determine the clonal lineage of a $P$. infestans isolate within $2 \mathrm{~h}$ (49), allowing growers to make informed management decisions based on the characteristics of each lineage. Although insensitivity to fungicide likely has the greatest influence on the management of late blight, results from this study may help to further refine management at the field level. For example, the poor sporulation of isolates representing the US24 lineage on tomato combined with attenuated LGR suggest that, if US-24 was the only lineage in a region, tomato growers may not need as frequent of applications of fungicides. However, if US-23 was in the region, aggressive tomato late blight management measures would be warranted, because this lineage sporulates and grows well on tomato. Epidemics caused by US-23 progress quickly, whereas the progression of epidemics caused by US-24 occurs slowly, suggesting that US-23 might be best managed, initially, by selective crop destruction but the US-24 lineage might be kept from spreading through the diligent use of fungicides.

\section{ACKNOWLEDGMENTS}

This work was supported, in part, by Hatch Formula Funds granted Dr. A. J. Gevens at the University of Wisconsin-Madison and a Wisconsin Potato Industry Board-Wisconsin Distinguished Graduate Fellowship awarded to A. C. Seidl Johnson. We thank P. Crump for invaluable assistance in understanding and working with SAS; S. Jordan, A. S. Perez, K. Cleveland, A. Mitchell, S. Donovan, L. Thomas, S. Schraber, and A. Turner for technical assistance in the University of Wisconsin-Potato and Vegetable Pathology Laboratory; and our Phytopathology reviewers and Senior Editor for critical review and helpful critiques.

\section{LITERATURE CITED}

1. Agrios, G. N. 2005. Plant Pathology. Elsevier Academic Press, Burlington, MA.

2. Anderegg, W. R. L., Prall, J. W., Harold, J., and Schneider, S. H. 2010. Expert credibility in climate change. Proc. Natl. Acad. Sci. USA. 107: 12107-12109.

3. Andrade-Piedra, J. L., Forbes, G. A., Shtienberg, D., Grünwald, N. J., Chacón, M. G., Taipe, M. V., Hijmans, R. J., and Fry, W. E. 2005. Qualification of a plant disease simulation model: Performance of the LATEBLIGHT model across a broad range of environments. Phytopathology 95:1412-1422.

4. Andrade-Piedra, J. L., Hijmans, R. J., Forbes, G. A., Fry, W. E., and Nelson, R. J. 2005. Simulation of potato late blight in the Andes. I: Modification and parameterization of the LATEBLIGHT model. Phytopathology 95:1191-1199.

5. Andrade-Piedra, J. L., Hijmans, R. J., Juárez, H. S., Forbes, G. A., Shtienberg, D., and Fry, W. E. 2005. Simulation of potato late blight in the Andes. II: Validation of the LATEBLIGHT model. Phytopathology 95: 1200-1208.

6. Anonymous. 2014. USABlight: A National Project on Tomato and Potato Late Blight in the United States (www.usablightorg).

7. Antonovics, J., and Alexander, H. M.1989. The concept of fitness in plantfungal pathogen systems. In: Plant Disease Epidemiology, Vol. 2. K. J. Leonard and W. E. Fry, eds. McGraw-Hill, Chicago, IL.

8. Aylor, D. E., Fry, W. E., Mayton, H., and Andrade-Piedra, J. L. 2001. Quantifying the rate of release and escape of Phytophthora infestans sporangia from a potato canopy. Phytopathology 91:1189-1196.

9. Blandón-Díaz, J. U., Forbes, G. A., Andrade-Piedra, J. L., and Yuen, J. E. 2011. Assessing the adequacy of the simulation model LATEBLIGHT under Nicaraguan conditions. Plant Dis. 95:839-846.
10. Bruhn, J. A., and Fry, W. E. 1981. Analysis of potato late blight epidemiology by simulation modeling. Phytopathology 71:612-616.

11. Caten, C. E., and Jinks, J. L. 1968. Spontaneous variability of a single isolate of Phytophthora infestans. I. Cultural variation. Can. J. Bot. 46: 329-348.

12. Crosier, W. 1934. Studies in the biology of Phytophthora infestans (Mont.) de Bary. Cornell Univ. Agric. Exp. Stn. Memoir 155.

13. Danies, G., Small, I. M., Myers, K., Childers, R. A., and Fry, W. E. 2013. Phenotypic characterization of recent clonal lineages of Phytophthora infestans in the United States. Plant Dis. 97:873-881.

14. Deahl, K. L., Inglis, D. A., and DeMuth, S. P. 1993. Testing for resistance to metalaxyl in Phytophthora infestans isolates in northwestern Washington. Am. Potato J. 70:779-795.

15. Derie, M. L., and Inglis, D. A. 2001. Persistence and complex virulences in populations of Phytophthora infestans in western Washington. Phytopathology 91:606-612.

16. Doster, M. A., Milgroom, M. G., and Fry, W. E. 1990. Quantification of factors influencing potato late blight suppression and selection for metalaxyl resistance in Phytophthora infestans: A simulation approach. Phytopathology 80:1190-1198.

17. Erwin, D. C., and Ribeiro, O. K. 1996. Phytophthora Diseases Worldwide. American Phytopathological Society Press, St. Paul, MN.

18. Fry, W. E., and Goodwin, S. B. 1997. Re-emergence of potato and tomato late blight in the United States. Plant Dis. 81:1349-1357.

19. Gallegly, M. E., and Hong, C. 2008. Phytophthora: Identifying Species by Morphology and DNA Fingerprints. American Phytopathological Society Press, St. Paul, MN.

20. Gavino, P. D., Smart, C. D., Sandrock, R. W., Miller, J. S., Hamm, P. B., Lee, T. Y., Davis, R. M., and Fry, W. E. 2000. Implications of sexual reproduction for Phytophthora infestans in the United States: Generation of an aggressive lineage. Plant Dis. 84:731-735.

21. Gevens, A. J., and Seidl, A. C. 2013. First report of late blight caused by Phytophthora infestans clonal lineage US-22 on tomato and potato in Wisconsin. Plant Dis. 97:432.

22. Gevens, A. J., and Seidl, A. C. 2013. First report of late blight caused by Phytophthora infestans clonal lineage US-23 on tomato and potato in Wisconsin, United States. Plant Dis. 97:839.

23. Gevens, A. J., and Seidl, A. C. 2013. First report of late blight caused by Phytophthora infestans clonal lineage US-24 on potato (Solanum tuberosum) in Wisconsin. Plant Dis. 97:152.

24. Golas, T. M., van der Weerden, G. M., van den Berg, R. G., Mariani, C., and Allefs, J. J. H. M. 2010. Role of Solanum dulcamara L. in potato late blight epidemiology. Potato Res. 53:69-81.

25. Goodwin, S. B., Cohen, B. A., and Fry, W. E. 1994. Panglobal distribution of a single clonal lineage of the Irish potato famine fungus. Proc. Natl. Acad. Sci. USA. 91:11591-11595.

26. Goodwin, S. B., Drenth, A., and Fry, W. E. 1992. Cloning and genetic analyses of two highly polymorphic, moderately repetitive nuclear DNAs from Phytophthora infestans. Curr. Genet. 22:107-115.

27. Goodwin, S. B., Fry, W. E., and Schneider, R. E. 1995. Use of celluloseacetate electrophoresis for rapid identification of allozyme genotypes of Phytophthora infestans. Plant Dis. 79:1181-1185.

28. Goodwin, S. B., Smart, C. D., Sandrock, R. W., Deahl, K. L., Punja, Z. K., and Fry, W. E. 1998. Genetic change within populations of Phytophthora infestans in the United States and Canada during 1994 to 1996: Role of migration and recombination. Phytopathology 88:939-949.

29. Goth, R. W. 1981. An efficient technique for prolonged storage of Phytophthora infestans. Am. Potato J. 58:257-260.

30. Grönberg, L., Andersson, B., and Yuen, J. E. 2012. Can weed hosts increase aggressiveness of Phytophthora infestans on potato? Phytopathology 102:429-433.

31. Groves, C. L. 2002. Characterization of Phytophthora infestans from Maine during 1999 and 2000. Am. J. Potato Res. 79:325-333.

32. Guenthner, J. F., Michael, K. C., and Nolte, P. 2001. The economic impact of potato late blight on US growers. Potato Res. 44:121-125.

33. Hartl, D. L., and Clark, A. G. 1997. Principles of Population Genetics, 3rd ed. Sinauer Associates, Sunderland, MA.

34. Haverkort, A. J., Boonekamp, P. M., Hutten, R., Jacobsen, E., Lotz, L. A. P., Kessel, G. J. T., Visser, R. G. F., and van der Vossen, E. A. G. 2008. Societal costs of late blight in potato and prospects of durable resistance through cisgenic modification. Potato Res. 51:47-57.

35. Haverkort, A. J., Struik, P., Visser, R., and Jacobsen, E. 2009. Applied biotechnology to combat late blight in potato caused by Phytophthora infestans. Potato Res. 52:249-264.

36. Hodgson, W. A., and Grainger, P. N. 1964. Culture of Phytophthora infestans on artificial media prepared from rye seeds. Can. J. Plant Sci. 44:583.

37. Hu, C.-H., Perez, F. G., Donahoo, R. S., McLeod, A., Myers, K., Ivors, K., Secor, G., Roberts, P. D., Deahl, K. L., Fry, W. E., and Ristaino, J. B. 2012. 
Recent genotypes of Phytophthora infestans in the eastern United States reveal clonal populations and reappearance of mefenoxam sensitivity. Plant Dis. 96:1323-1330.

38. Kadish, D., and Cohen, Y. 1988. Fitness of Phytophthora infestans isolates from metalaxyl-sensitive and -resistant populations. Phytopathology 78: 912-915.

39. Kalischuk, M., Al-Mughrabi, K. I., Peters, R. D., Howard, R. J., Platt, H. W., and Kawchuk, L. M. 2012. Genetic composition of Phytophthora infestans in Canada reveals migration and increased diversity. Plant Dis. 96:1729-1735.

40. Kato, M., Mizubuti, E. S., Goodwin, S. B., and Fry, W. E. 1997. Sensitivity to protectant fungicides and pathogenic fitness of clonal lineages of Phytophthora infestans in the United States. Phytopathology 87: 973-978.

41. Kawchuk, L. M., Howard, R. J., Peters, R. D., and Al-Mughrabi, K. I. 2011. First report of Phytophthora infestans genotype US23 causing late blight in Canada. Plant Dis. 95:873.

42. Lamour, K. H., and Hausbeck, M. K. 2001. Investigating the spatiotemporal genetic structure of Phytophthora capsicum in Michigan. Phytopathology 91:973-980.

43. Laggard, D. E., Lee, T. Y., and Fry, W. E. 1995. Pathogenic specialization in Phytophthora infestans: Aggressiveness on tomato. Phytopathology 85: 1356-1361.

44. Marshall-Farrar, K., McGrath, M., James, R., and Stevenson, W. 1998. Characterization of Phytophthora infestans in Wisconsin from 1993 to 1995. Plant Dis. 82:434-436.

45. Miller, J. S., Johnson, D. A., and Hamm, P. B. 1998. Aggressiveness of isolates of Phytophthora infestans from the Columbia Basin of Washington and Oregon. Phytopathology 88:190-197.
46. Mizubuti, E. S. G., and Fry, W. E. 1998. Temperature effects on developmental stages of isolates from three clonal lineages of Phytophthora infestans. Phytopathology 88:837-843.

47. R Development Core Team. 2009. R: A language and environment for statistical computing. R Foundation for Statistical Computing, Vienna. http://www.R-project.org

48. Ristaino, J. B. 2010. The 2009 potato and tomato late blight epidemics: Genealogical history, multiple sources and migration events. (Abstr.) Phytopathology 100:S161.

49. Seidl, A. C., and Gevens, A. J. 2013. Characterization and distribution of three new clonal lineages of Phytophthora infestans causing late blight in Wisconsin from 2009 to 2012. Am. J. Potato Res. 90:551-560.

50. Seidl, A. C., Mitchell, A. J., Gevens, A. J. 2012. Assessing fitness of new Phytophthora infestans clonal lineages by comparing sporangial production on tomato leaves. (Abstr.) Phytopathology 102:S5.9.

51. Tooley, P. W., Sweigard, J. A., and Fry, W. E. 1986. Fitness and virulence of Phytophthora infestans isolates from sexual and asexual populations. Phytopathology 76:1209-1212.

52. Visker, M. H. P. W., Keizer, L. C. P., Budding, D. J., Van Loon, L. C., Colon, L. T., and Struik, P. C. 2003. Leaf position prevails over plant age and leaf age in reflecting resistance to late blight in potato. Phytopathology 93:666-674.

53. Vleeshouwers, V. G. A. A., van Dooijweert, W., Paul Keizer, L. C., Sijpkes, L., Govers, F., and Colon, L. T. 1999. A laboratory assay for Phytophthora infestans resistance in various Solanum species reflects the field situation. Eur. J. Plant Pathol. 105:241-250.

54. Zeileis, A., and Grothendieck, G. 2005. zoo: S3 Infrastructure for regular and irregular time series. J. Stat. Softw. 14:1-27. http://www.jstatsoft.org/ v14/i06/ 